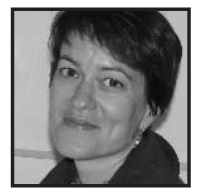

\title{
Early Childhood Literacy and the Sense of Play
}

\author{
Geneviève Côté
}

\section{ABSTRACT}

The author relates some of her experiences as a children's book author/illustrator visiting schools, observing that in early childhood, creativity and sense of play are essential tools for teaching and learning. Believing that images and words play an equally important role in the learning process, she also includes a visual statement that early childhood literacy is empowering ...

"You see, I don't believe that libraries should be drab places where people sit in silence, and that's been the main reason for our policy of employing wild animals as librarians."

—Monty Python's Flying Circus (1969)

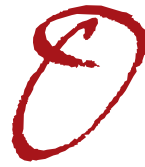

nce upon a time, on Halloween morning, a scary-looking monster (who was, unexpectedly, gentle and sweet) carved up a pumpkin in which a mouse had built her home. Unfortunately, that mouse was really an evil witch.

Thus started the story a dozen kindergarteners came up with and that $\mathrm{l}$, the visiting author/illustrator, sketched on the board step by step in their wake. I was leading a favorite library activity of mine, once again observing how children who do not yet have reading or writing skills will easily turn into authors. They were delighted with the story they were making up, and I thought this might well boost their overall outlook on books-which was in fact the reason I was there. I was also truly curious to hear how that story would unfold. The gentle scary-looking monster was in trouble, and the children appeared momentarily stuck. 
After a first tentative suggestion to Call Mommy For Help, they eventually adopted a seemingly better-albeit simple-solution. Thus the Monster apologized for disturbing the Witch-mouse, who in turn, unused to such good manners, rewarded the Monster by granting him one special wish. Through story-making, these four-year-olds had come up with a creative solution that might well fit real-life problems in the schoolyard.

As a children's book author/illustrator, I get to meet children in primary schools, kindergartens and libraries. I have become increasingly interested in early childhood and emergent literacy—specifically in how literacy can empower children and foster their creativity. Similarly, from what I have witnessed around classrooms, it also appears especially effective to appeal to the students' creativity and sense of play while teaching.

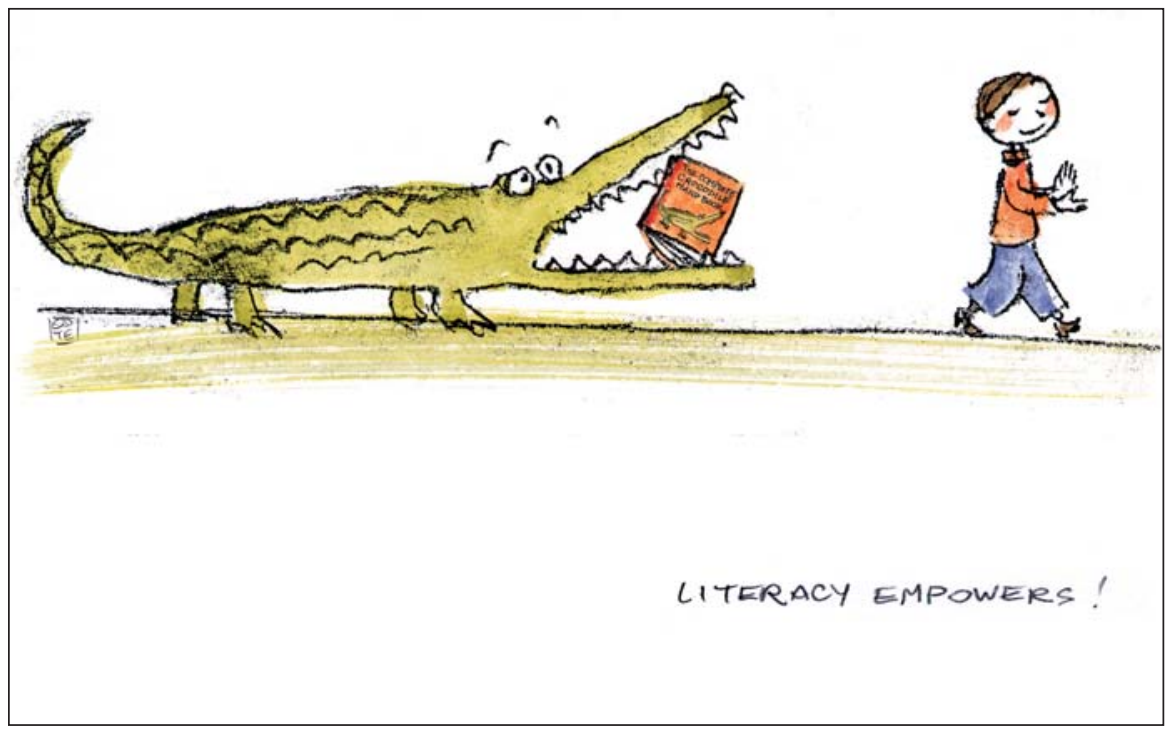

Fig. 1:The complete crocodile hand book

Children can certainly experience and benefit from the joy of reading long before they have reading skills. They enjoy being read to, repeating a rhyme, enacting a character from a favourite story, looking at pictures or making images of their own.

Kindergarteners also often love taking part in book activities that involve physical exercise. (I recall once coming upon a roomful of them, lying on their back 
and pedaling enthusiastically on imaginary bicycles alongside their favorite book character during storytelling time. Quite a sight!) In my opinion, if they are introduced early in any such way to books or stories they are likely to enjoy, they stand a better chance to be interested in reading altogether.

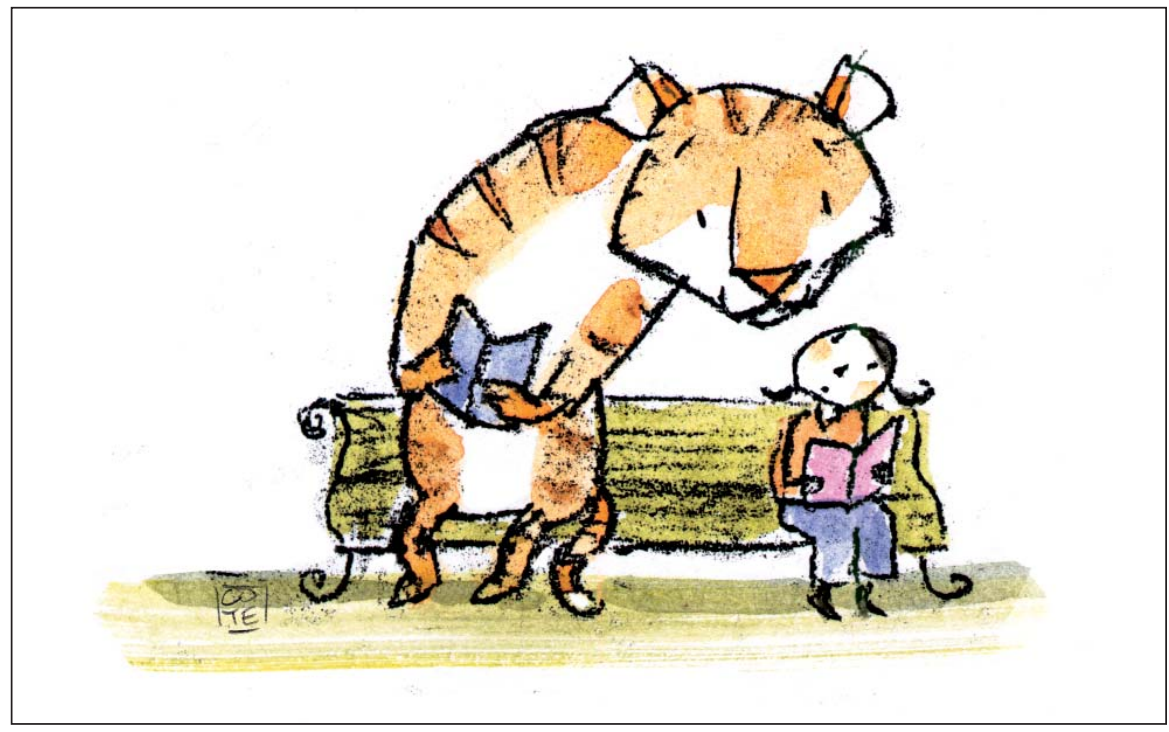

Fig. 2: Reading time with tiger

Being an author and illustrator, I believe that images and words play an equally important role in the learning process during early years. Children draw before they can write, and as they later learn to trace letters, they often like to work those, undifferentiated, into their drawings. Both words and images are after all effective languages for translating the world - the inside world, exposed for others or sublimated for one's own benefit, as well as the outside world, tamed and scaled down to sizable bites.

This is why, when leading library activities, I often ask every student to draw at least one scene from the story created collectively. These drawings are always incredibly varied, and illustrate quite effectively how reading is very much about making sense of words and images on one's own.

Similarly, in my practice as an author, I trust and expect a reader to be allowed to co-create, in some measure, the story as he or she reads it. So while I fret 
over language levels and sentence pacing to match my readers' skill levels, or create illustrations, I also do my best to leave room for the reader's input.

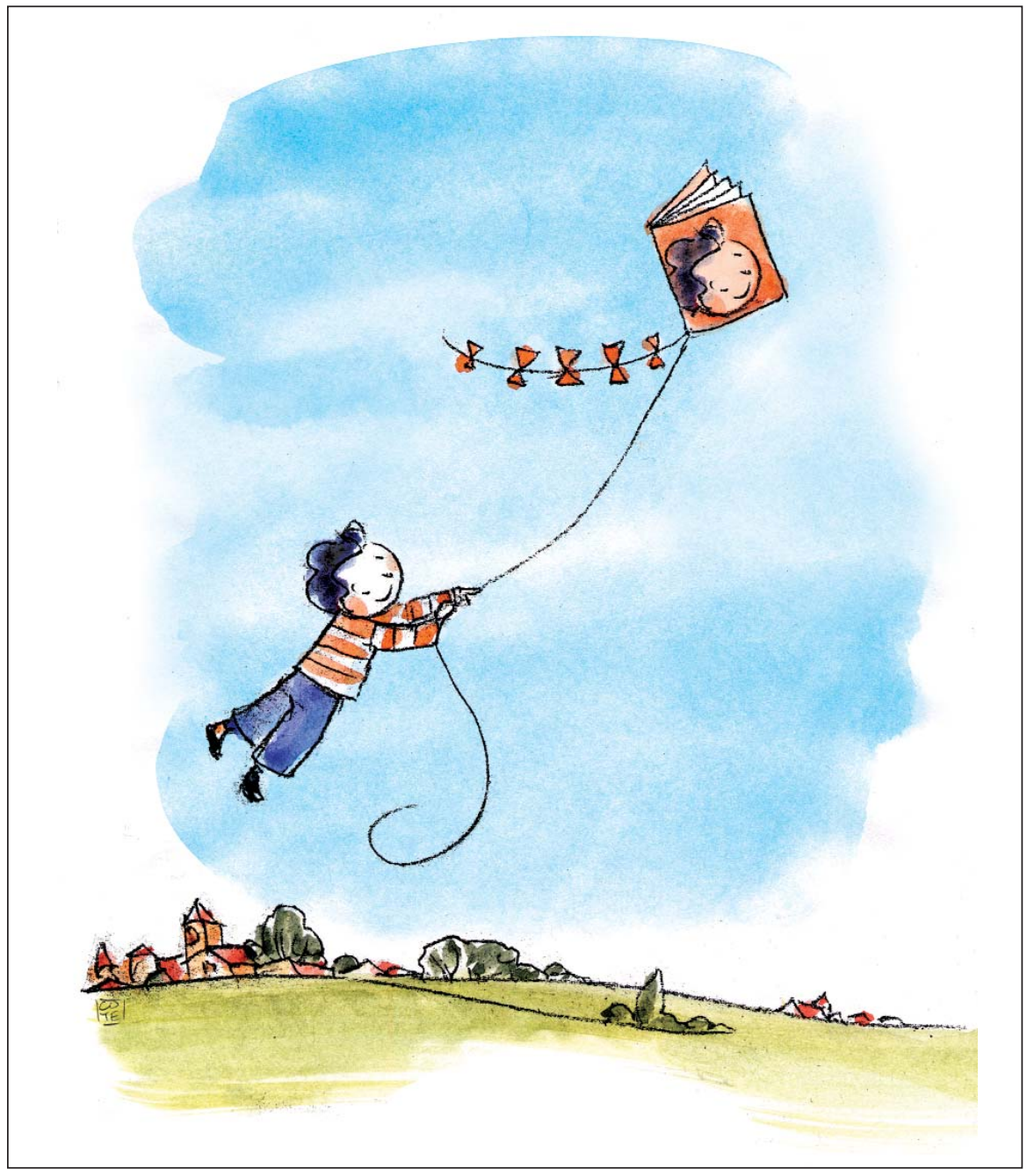

Fig. 3: Carried away by the magic of words

My kindergarteners' Halloween story had a happy ending, of course, and the monster was granted one special wish. My special wish now is that throughout their learning years, these children's creativity and sense of play will be nurtured as well, and that they will always know how to meet witches and monsters head on. 


\section{Notes}

For anyone interested in children literacy, I suggest the Web site of the Association pour la Création Littéraire chez les Jeunes: www.projetjeunesse.com. This nonprofit organization promotes intercultural collaboration between students from Frenchspeaking countries all over the world (Mali, Côte d'Ivoire, Haiti, Canada, and several others). Through Projet-Jeunesse, a participating classroom, in Mali, for instance, might create and write an original tale to be illustrated by another classroom in Quebec or vice versa. Texts and images are then published and distributed with the help of teachers and volunteers throughout the communities and on the Web site.

While these stories vary greatly, they are often thought provoking, sometimes poignant. Children share stories of love and friendship, as well as of bullying or exclusion, poverty, or AIDS, for those who live in countries where it is endemic, and where such stories can become helpful tools for healthcare and social change.

\section{References}

Monty Python's Flying Circus (1969). Series 1, Episode 10 (originally aired December 21, 1969). Retrieved November 4, 2009, from http://www.carl-abrc.ca/publications /elert/2007/elert212-e.html (see heading: Monty Python's gorilla librarian skit).

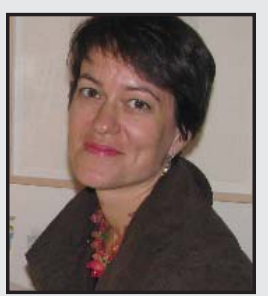

Geneviève Côté graduated from Concordia University in 1987 and shortly after started working as a freelance illustrator for publications in Canada and the United States such as the New York Times and l'Actualité. Eventually, her interest in children's literature took over, and she illustrated several books, earning a few awards, including the Governor General's Award in 2007. In addition, Geneviève writes picture books of her own, and her latest, Me and You, was published in 2009. She is frequently invited to meet young students in schools and libraries.

LINK TO:

http://www.genevievecoteillustration.com/ 